\title{
PROLONGED SARCOTUBULAR REGENERATIVE RESPONSE IN FROG SARTORIUS MUSCLE
}

\author{
Kimihisa TAKEDA \\ Laboratory of Physiology, Faculty of Education, \\ Tottori University, Tottori, 680 Japan
}

\begin{abstract}
The sarcotubular system of frog sartorius muscle fibers is found to generate a prolonged depolarizing regenerative response under appropriate experimental conditions. It is shown from a point-voltage clamp analysis that the inward current component responsible for the response lasts on depolarization for hundreds of milliseconds and reverses its sign when an equilibrium potential is exceeded. The sarcotubular response occurs in F-Ringer solution and is enhanced with EDTA. It also occurs in normal or propionate-Ringer solution containing EDTA without great change in the equilibrium potential. The response is inhibited reversibly with picrotoxin. Partial replacement of $\mathrm{Na}$ by $\mathrm{K}$ in the propionate-Ringer solution reduces the inward current component which suggests that $\mathrm{Na}$ may be the responsible ions.
\end{abstract}

It may be necessary that the membrane properties of the sarcotubular system (SANDOw, 1970), the site of inward spread of sarcolemmal excitation, are clarified to aid in understanding excitation-contraction coupling in twitch muscle fibers. Indirect evidence shows that the transverse tubular system may have a Na-dependent regenerative process comparable to that of the sarcolemma (COSTANTIN, 1970; Bezanilla et al., 1972; CAPUTO and DiPolo, 1973; BAStiAn and NaKaJima, 1974). On the other hand, the sarcotubular system shows electrical and pharmacological properties which are distinct from those of the sarcolemma (EISENBERG and GAGE, 1969; GAGE and EISENBERG, 1969; TAKEDA, 1975a, b, c).

This paper deals with a voltage- and time-dependent conductance increase of the sarcotubular system which induces prolonged depolarizing regenerative response (designated hereafter as the sarcotubular response) under appropriate experimental conditions. Point-voltage clamp analysis revealed an inward current component responsible for the sarcotubular response, which is conveniently labelled $I_{\mathrm{i}}$. The sarcolemma lacks comparable response, and thus reveals a unique property of the sarcotubular system. Preliminary accounts of some of these results

Received for publication March 19, 1977

竹田公久 
have appeared elsewhere (TAKEDA and OOMURA, 1968, 1970a, 1971b, 1972; TAKEDA, 1975d, 1976).

\section{METHODS}

The sartorius muscle from Rana catesbiana was isolated, and mounted on a paraffin block in a Lucite chamber. Only surface fibers were penetrated using conventional two-intracellular-microelectrode technique. Capillary glass microelectrodes filled with $3 \mathrm{M} \mathrm{KCl}$ and with a resistance of about $10 \mathrm{M} \Omega$, were used for voltage recording; for passing current, electrodes were filled with $2 \mathrm{M}$ potassium citrate and had a resistance of about $5 \mathrm{M} \Omega$. For constant current stimulation, current was applied through a $100 \mathrm{M} \Omega$ resistor. The intracellular voltage was led through a FET-IC preamplifier to one trace of a dual-trace oscilloscope for display and photographic recording, and the total electrode current was similarly recorded as a potential difference across a $100 \mathrm{k} \Omega$ resistor. For point-voltage clamp experiments, a voltage clamp device was constructed using IC, FET and vacuum tubes; it had a rise time of about $100 \mu \mathrm{sec}$ for a $100 \mathrm{mV}$ step change of clamped voltage. A holding potential near $-100 \mathrm{mV}$ was used. Under these experimental conditions the membrane potential upon polarization varies with distance from the current electrode. However, the methods used are useful for the present rather qualitative analysis.

Table 1. Composition of solutions.

$(\mathrm{mm})$

\begin{tabular}{cccccccccc}
$\begin{array}{c}\text { Solution } \\
\text { reference }\end{array}$ & $\mathrm{Na}^{+}$ & $\mathrm{K}^{+}$ & $\mathrm{Ca}^{++}$ & $\mathrm{Cl}^{-}$ & $\mathrm{F}^{-}$ & $\mathrm{C}_{3} \mathrm{H}_{5} \mathrm{O}_{2}{ }^{-}$ & $\mathrm{HPO}_{4}{ }^{--}$ & $\mathrm{H}_{2} \mathrm{PO}_{4}{ }^{-}$ & $\mathrm{HCO}_{3}^{-}$ \\
\hline $\mathrm{A}$ & 116.34 & 2.5 & 2 & 118 & - & - & $1.84^{*}$ & $1.16^{*}$ & - \\
$\mathrm{B}$ & 117.96 & 2.05 & - & 2.05 & 117.2 & - & - & - & 0.76 \\
$\mathrm{C}$ & 119.33 & 2.56 & - & 2.56 & 114.36 & - & 1.89 & 1.19 & - \\
$\mathrm{D}$ & 116.34 & 2.5 & 2 & 6.5 & - & 111.5 & 1.84 & 1.16 & - \\
\hline
\end{tabular}

* Values for the solution at $\mathrm{pH}$ 7.0. Their ratio adjusted for other $\mathrm{pH}$.

The compositions of Ringer solutions used are shown in Table 1. Tetrodotoxin $(1 \mu \mathrm{g} / \mathrm{ml})$ was added to all solutions to eliminate any effects of the sarcolemmal $\mathrm{Na}$ channel. Ethylenediaminetetraacetic acid disodium salt (EDTA) was simply added to solutions $\mathrm{C}$ and $\mathrm{D}$, while the $\mathrm{pH}$ was readjusted electrometrically with $\mathrm{NaOH}$ to a value between 5.6 and 7.0 when EDTA was added to solution A or ethyleneglycoldiethyletherdiaminetetraacetic acid (EGTA) was added to solution D. Picrotoxin was simply added to the solutions. The isolated muscles were stored overnight in a refrigerator when measurements were required the next day. For glycerol treatment, the method of earlier workers (EISENBERG and EISENBERG, 1968; Howell, 1969) was used. The experiments were performed at room temperature $\left(21-23^{\circ} \mathrm{C}\right)$. 


\section{RESULTS}

\section{Generation of the sarcotubular response}

Unless otherwise stated, electrical measurements could be made successfully without contraction difficulties even during large depolarizing voltage steps after several hours of equilibration of muscle fibers in the Ringer solutions used. Figure 1 shows typical records of the sarcotubular response obtained in the F-Ringer solution (solution B). The fibers had low resting potential in the solution. Its normal value was restored at the recording site by injecting DC prior to stimulation. The sarcotubular response consisted of rising, plateau and falling phases, and a negative afterpotential resembling a cardiac action potential. The response threshold in the solution was about $-50 \mathrm{mV}$. The peak membrane potential was slightly inside negative. The duration of the plateau phase depended on stimulation interval and ranged from hundreds of milliseconds to over $1 \mathrm{sec}$. The afterpotential lasted for more than $1 \mathrm{sec}$. The sarcotubular response is all-or-none and regenerative as evidenced by its generation even after termination of a stimulating pulse (Fig. 1B, trace 2).
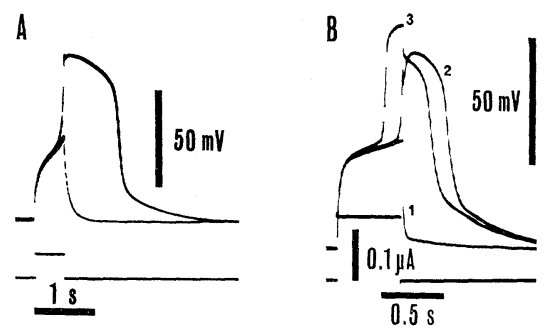

Fig. 1. Records of the sarcotubular response (upper traces, depolarization upward) induced by threshold outward current pulses (lower trace) in solution B. Fibers hyperpolarized prior to stimulation from -29 (resting potential) to $-90 \mathrm{mV}$ in $\mathrm{A}$, from -43 to $-85 \mathrm{mV}$ in B. Tetrodotoxin was added to all solutions used.

In the absence of prior restoration of normal resting potential, total currentvoltage $(\mathrm{I}-\mathrm{V})$ relations of these low resting potential fibers showed only minor non-linearity and the sarcotubular response could not be generated by outward current pulses. Occasionally, however, the sarcotubular response was generated on termination of hyperpolarizing pulses of sufficient amplitude and duration. In a fiber having a resting potential of $-36 \mathrm{mV}$, a 5 -sec current pulse hyperpolarizing to $-100 \mathrm{mV}$ was critical for the generation of such a response. Thus, a normal resting potential is prerequisite for the generation of the sarcotubular response and maintained depolarization inactivates the responsible conductance increase.

\section{Inward current}

A sufficient 1-sec step depolarization elicited $I_{\mathrm{i}}$ after an initial capacitative surge, seen as a dip in concurrent slowly inactivating outward current or as an 
inward total current in the point-voltage clamp records obtained in various solutions (Fig. 2). The resting potential was low in these fibers and a holding potential near $-100 \mathrm{mV}$ was used. The recording of inward total current assures the
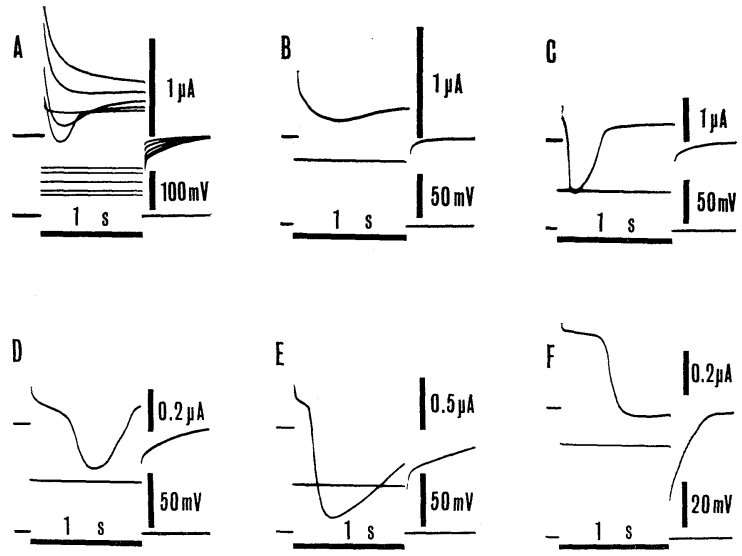

Fig. 2. Point-voltage clamp records of the sarcotubular response at, except for A, just above the threshold. Upper trace, total current (outward current upward); lower trace, voltage (depolarization upward). $\mathrm{A}$, in solution $\mathrm{B} ; \mathrm{B}$, in solution $\mathrm{C}$; $\mathrm{C}$, in solution $\mathrm{C}$ containing $1 \mathrm{mM}$ EDTA; D, in solution D containing $4 \mathrm{~mm}$ EDTA; $\mathrm{E}$, in solution D containing $10 \mathrm{~mm}$ EGTA; F, in solution A containing $4 \mathrm{~mm}$ EDTA. From A to F, resting potential of fibers, $-56,-37,-42,-32,-40$ and $-30 \mathrm{mV}$; holding potential, $-109,-102,-102,-100,-100$ and $-100 \mathrm{mV}$. From B to F, membrane potential during voltage step, $-28,-58,-53.5,-57$ and $-58.5 \mathrm{mV}$.

presence of $I_{\mathrm{i}}$. After reaching a peak, $I_{\mathrm{i}}$ was gradually inactivated during the step depolarization. The main part of $I_{1}$ lasted for hundreds of milliseconds or more, comparable to the plateau duration of the voltage response. At just above the threshold, $I_{\mathrm{i}}$ was initiated with a great delay. The inward tail current $\left(I_{\text {tai1 }}\right)$ associated with the sarcotubular response (see its absence in glycerol-treated fiber; Fig. 6) is seen on termination of the step depolarization. Both the threshold and the amplitude of $I_{\mathrm{i}}$ varied considerably with the Ringer solutions used.

The inward total current due to $I_{\mathrm{i}}$ and $I_{\mathrm{tai} 1}$ are seen in the $\mathrm{I}-\mathrm{V}$ relations in the propionate-Ringer solution (solution D) containing $4 \mathrm{~mm}$ EDTA (Fig. 3). On increasing depolarization the sign of $I_{\mathrm{i}}$ was reversed by exceeding an equilibrium potential, as evidenced by the conversion of the dip in outward current to a hump, while $I_{\mathrm{ta} \text { i1 }}$ remained as inward (Fig. 3 , inset records). At $+8 \mathrm{mV}$ a minor hump is barely recognizable in this fiber (arrow in inset record c). It appears that the equilibrium potential obtained in this and other Cl-deficient solutions is slightly inside negative, corresponding to the peak of the voltage response.

Effects of anions, cations, buffers and chelates

F-Ringer solutions. The sarcotubular response was first found in the F- 
Ringer solution buffered with bicarbonate (solution B). In the solution, the threshold for $I_{\mathrm{i}}$ was about $-50 \mathrm{mV}$. The $I_{\mathrm{i}}$ recorded at just above the threshold was comparable in amplitude to the concurrent outward current (Fig. 2A). When the phosphate buffer (solution $C$ ) replaced the bicarbonate, the threshold was raised to above $-40 \mathrm{mV}$, and $I_{\mathrm{i}}$ became much less prominent (Fig. 2B). Occasionally $I_{\mathrm{i}}$ was scarcely noticeable during depolarizations in solution $\mathrm{C}$, but $I_{\mathrm{tai}}$ recorded indicated that the sarcotubular conductance increase did occur.
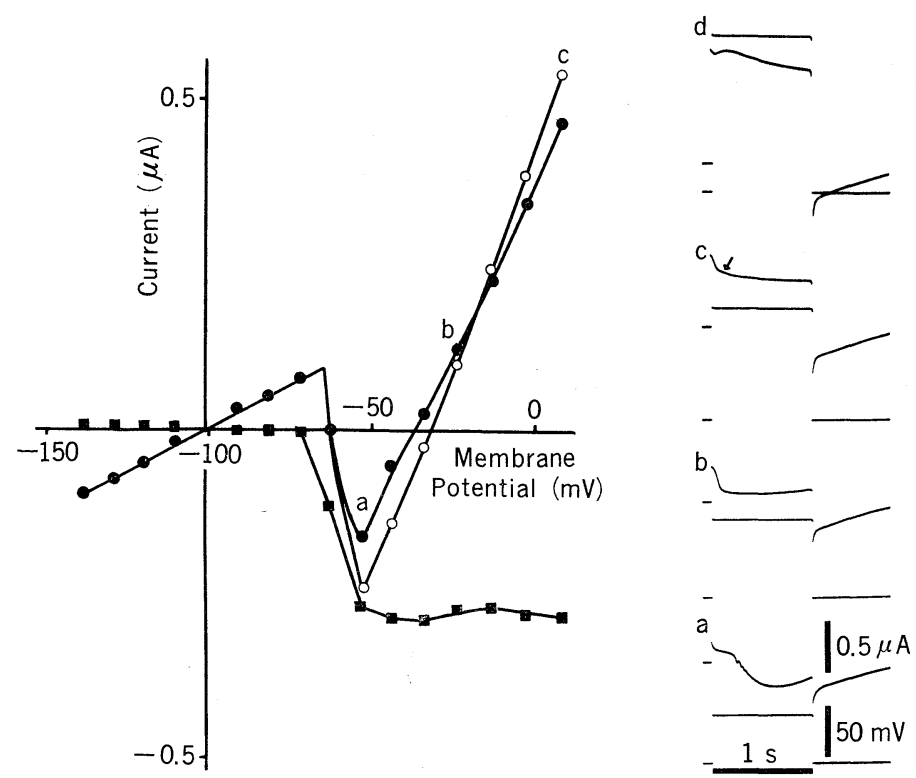

Fig. 3. Total current-voltage relations in solution D containing $4 \mathrm{~mm}$ EDTA. Pointvoltage clamp method is used in this and subsequent figures. Open circles, response peak (at $150 \mathrm{msec}$ ); filled circles, at $1 \mathrm{sec}$; squares, at $75 \mathrm{msec}$ after termination of voltage steps. Resting potential, $-27 \mathrm{mV}$; holding potential, $-101 \mathrm{mV}$. Inset records show total current (upper trace, outward current upward) and voltage (lower trace, depolarization upward). Inset records a-c correspond to points labelled a-c; d, depolarized to $+53.5 \mathrm{mV}$ (not plotted).

Addition of $1 \mathrm{~mm}$ EDTA to solution $\mathrm{C}$ greatly enhanced the sarcotubular response (Fig. 2C). The threshold was lowered to below $-60 \mathrm{mV}$ and large inward total current was recorded.

Propionate-Ringer solutions. In the propionate-Ringer solution (solution D) containing no EDTA the fibers maintained normal resting potential. On depolarization up to about $-45 \mathrm{mV}$ these fibers did not produce the sarcotubular response. On further depolarization vigorous contractions prevented the electrical measurements. With the addition of $4 \mathrm{~mm}$ EDTA the resting potential of the fibers was reduced to about $-30 \mathrm{mV}$. These fibers produced the sarcotubular 
response (Fig. 2D). The threshold was about $-60 \mathrm{mV}$. The inward total current was recorded, of which the amplitude was smaller than that in solution $\mathrm{C}$ containing $1 \mathrm{~mm}$ EDTA.

Addition of $10 \mathrm{~mm}$ EGTA to solution D resulted in effects similar to those of the addition of EDTA. The larger $I_{\mathrm{i}}$ recorded in the solution is probably due to a higher concentration of EGTA used (Fig. 2E). The muscles had to be stored for more than a day in this solution before the measurements, otherwise vigorous contractions, which were not seen in the solution containing EDTA, were encountered on large depolarization.

Chloride-Ringer solutions. In standard Ringer solution (solution A) in which the $\mathrm{pH}$ was lowered to 5.6 to reduce contractions (LoRKović, 1967), depolarizations up to $-40 \mathrm{mV}$ did not induce sarcotubular response. With the addition of $4 \mathrm{~mm}$ EDTA the resting potential of the fibers was reduced. The sarcotubular response was generated in the muscle stored in this solution for more than a day to avoid contraction difficulties (Fig. 2F). The threshold was about $-60 \mathrm{mV}$. The maximum $I_{\mathrm{i}}$ recorded was comparable in amplitude to the concurrent outward current. Figure 4 shows the I-V relations in solution $\mathrm{A}$ at $\mathrm{pH} 6.3$ and containing $5 \mathrm{~mm}$ EDTA. The equilibrium potential of $I_{\mathrm{i}}$ in the Cl-Ringer solution appears to be not much different from that in the Cl-deficient solutions used.

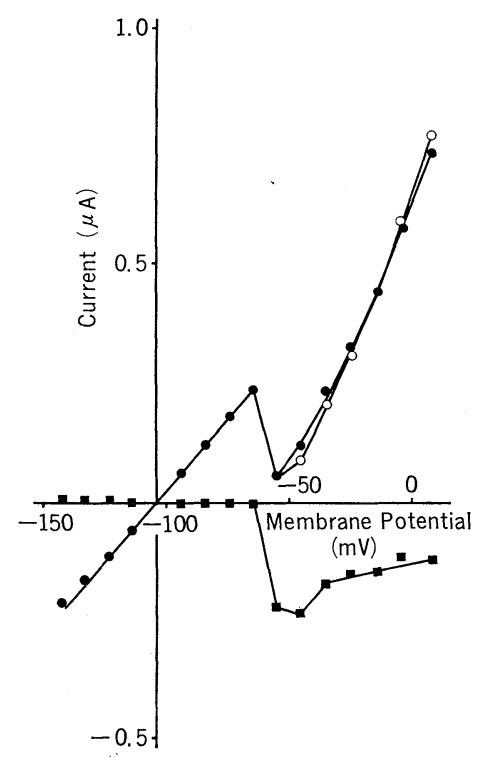

Fig. 4. Total current-voltage relations in solution A containing 5 mм EDTA. Resting potential, $-28 \mathrm{mV}$; holding potential, $-104 \mathrm{mV}$. For explanation of marks see legend in Fig. 3 (but response peak, at $200 \mathrm{msec}$ ).

Replacement of sodium by potassium. When $\mathrm{Na}$ in solution $\mathrm{D}$ containing $4 \mathrm{~mm}$ EDTA was partially replaced by isotonic $\mathrm{K}$, the maximum amplitude of $I_{\mathrm{i}}$ 
was reduced with the concentration effect of $\mathrm{Na}$ (Fig. 5). The experiment shown in Fig. 3 was performed as a control for the series shown in Fig. 5. $I_{\text {tail }}$ was also reduced but to a less extent. The response threshold was raised appreciably. The results suggest that the equilibrium potential of $I_{\mathrm{i}}$ may be altered toward the inside negative direction, which results in a reduction in $I_{i}$, by the replacement of external $\mathrm{Na}$ by $\mathrm{K}$.
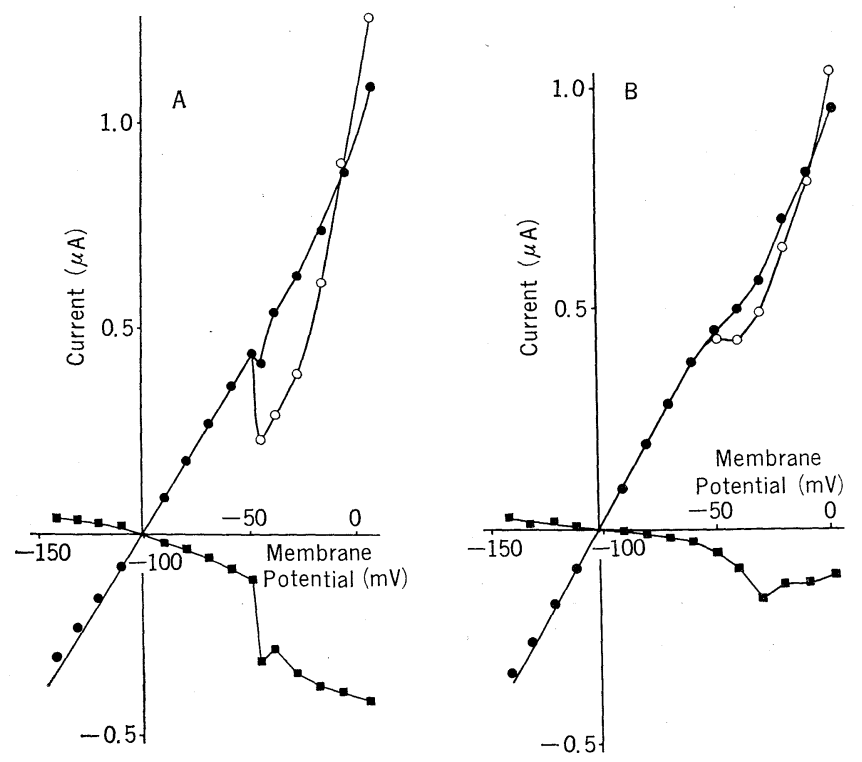

Fig. 5. Total current-voltage relations with reduced $\mathrm{Na}$ (61 $\mathrm{mm}$ in $\mathrm{A}, 33 \mathrm{~mm}$ in $\mathrm{B}$; replaced by $\mathrm{K}$ ) in solution $\mathrm{D}$ containing $4 \mathrm{~mm}$ EDTA. Resting potential of fibers, $-18 \mathrm{mV}$ (A), $-20 \mathrm{mV}$ (B); holding potential, $-101 \mathrm{mV}$ (A), $-102 \mathrm{mV}$ (B). For explanation of marks see legend in Fig. 3 (but response peak, at $200 \mathrm{msec}$ ).

\section{Conductance increase}

By superimposing small test current pulses, the effective conductance is found to increase during the sarcotubular response. In solution $\mathrm{B}$, the quick post-pulse potential changes in traces 1 and 3 of Fig. 1B indicate an increase in effective conductance of 3.17 times during the sarcotubular response. The slope conductances measured from linear I-V relations at hyperpolarized and depolarized states gave similar figures. In solution D containing $4 \mathrm{~mm}$ EDTA the effective slope conductance increased 5.2 times at the peak of the response (Fig. 3). These values may be equivalent to the increase in specific membrane conductance of 10 to 25 times if it occurred in the sarcolemma. However the specific value of the sarcotubular conductance increase may be difficult to determine due to the morphological and electrical complexities within the sarcotubular system. 
Sarcotubular system as generation site

The data of Fig. 6 was obtained under the same experimental conditions as those of Fig. 3 except that a glycerol-treated fiber was used. Since the contribution, if any, of the sarcotubular system should be small in glycerol-treated fibers (EISENBERG and EISENBERG, 1968), the I-V relations in Fig. 6 represent predominantly the properties of the sarcolemma. Depolarizations exceeding about $-50 \mathrm{mV}$ caused only sarcolemmal delayed rectification (TAKEDA, 1975b) in glycerol-treated fibers, which reached a peak at tens of milliseconds and was inactivated monotonically (Fig. 6, inset record b). Thus both $I_{\mathrm{i}}$ and $I_{\mathrm{tai1}}$ observed in intact fibers were absent in glycerol-treated fibers. Similar results were obtained with other Ringer solutions used. These results indicate that the sarcotubular response is generated in the sarcotubular system.
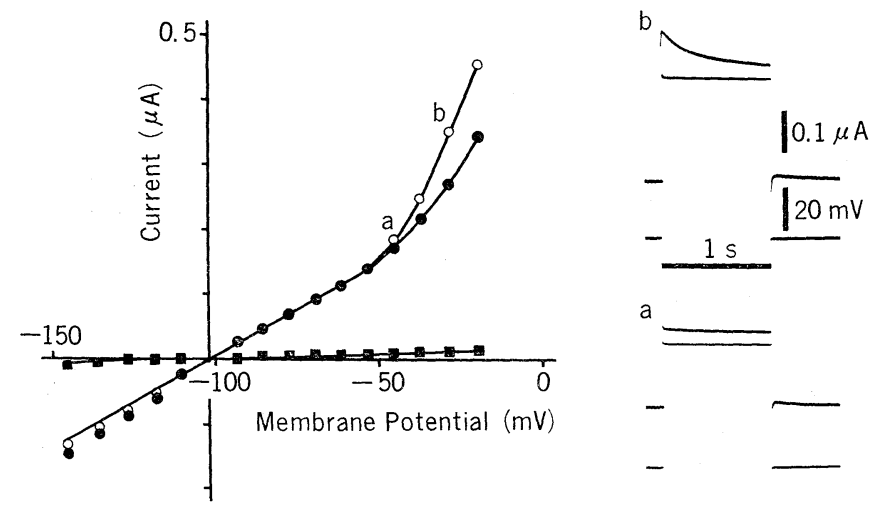

Fig. 6. Total current-voltage relations of a glycerol-treated fiber in solution D containing $4 \mathrm{~mm}$ EDTA. Open circles, at $50 \mathrm{msec}$; filled circles, at $1 \mathrm{sec}$; squares, at $75 \mathrm{msec}$ after voltage steps. Resting potential, $-34 \mathrm{mV}$; holding potential, $-102 \mathrm{mV}$.

\section{Reversible inhibition by picrotoxin}

Addition of $1 \mathrm{mg} / \mathrm{ml}$ picrotoxin to solution B blocked the sarcotubular response induced by current pulses. As shown in Fig. 7, both $I_{\mathrm{i}}$ and $I_{\mathrm{tai}}$ were almost completely blocked within $5 \mathrm{~min}$ after addition of $3 \mathrm{mg} / \mathrm{ml}$ picrotoxin to solution D containing $4 \mathrm{~mm}$ EDTA. On return to the solution containing no picrotoxin, incomplete recovery of $I_{\mathrm{i}}$, but not of $I_{\text {tail }}$, occurred at $5 \mathrm{~min}$. More than one-half hour was required for the reappearance of clear $I_{\mathrm{tai}}$, and even by this time the recovery of $I_{\mathrm{i}}$ was incomplete. These results indicate the selective inhibition by picrotoxin of the conductance increase responsible for the sarcotubular response, which is partially reversible. The I-V relations of intact fibers equilibrated in the solution containing $3 \mathrm{mg} / \mathrm{ml}$ picrotoxin are similar to those of glycerol-treated fibers in the solution containing no picrotoxin in that neither $I_{\mathrm{i}}$ nor $I_{\mathrm{tai} 1}$ is seen. 


\section{DISCUSSION}

The present results demonstrate for the first time a regenerative response generated specifically in the sarcotubular system. The properties of $I_{1}$ are in common with those of the sarcolemmal $\mathrm{Na}$ channel (ADRIAN et al., 1970) in its voltage- and time-dependency. However the time course of the former is much slower than that of the latter even if allowances should be made for the dispersion due to possible asynchronism in the former within the complex sarcotubular system.

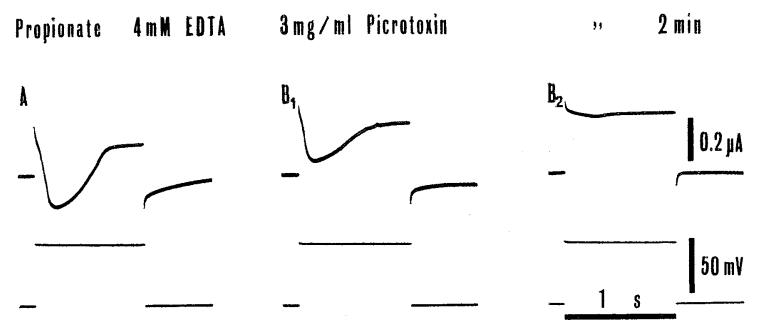

Fig. 7. Inhibition by picrotoxin of the inward current component of the sarcotubular response in solution D containing $4 \mathrm{~mm}$ EDTA. Upper trace, total current; lower trace, voltage. A, before picrotoxin; $B_{1}$, immediately after addition of $3 \mathrm{mg} / \mathrm{ml}$ picrotoxin; $\mathbf{B}_{2}$, after $2 \mathrm{~min}$. Resting potential, $-36 \mathrm{mV}$; holding potential, $-100 \mathrm{mV}$.

The alteration of the delayed rectification threshold by lyotropic anions has been reported in the frog sartorius muscle (KAO and STANFIELD, 1968). The observed variation in the threshold for the sarcotubular response with different Ringer solutions might reflect the variability in distribution within the sarcotubular system of the sarcotubular response and the incomplete voltage clamp of sarcotubular membranes rather than the difference in actual threshold at the response-generating membrane.

The apparent insensitivity of the equilibrium potential of $I_{\mathrm{i}}$ to the external $\mathrm{Cl}$ concentration appears to exclude the possibility that $\mathrm{Cl}$ ions are mainly responsible for $I_{\mathrm{i}}$, since the present results show that external ions affect the sarcotubular response. The occurrence of $I_{\mathrm{i}}$ in the absence of external divalent cation (in solutions B and C) makes it unlikely that any divalent cation is responsible for $I_{\mathrm{i}}$.

The effect of replacement of external $\mathrm{Na}$ by $\mathrm{K}$ to reduce $I_{\mathrm{i}}$ implies that either of these ions may be responsible. It might be argued that the temporal accumulation within the sarcotubular system of $\mathrm{K}$ ions that flowed out from the sarcoplasm during depolarization might make the $\mathrm{K}$ equilibrium potential at the responsegenerating membrane positive enough to induce inward $\mathrm{K}$ current even in low $\mathrm{K}$ solutions. If $I_{\mathrm{i}}$ represents $\mathrm{K}$ current, however, the replacement of external $\mathrm{Na}$ by K should augment $I_{\mathrm{i}}$ (BELTON and GRUNDFEST, 1962). The observed reduction in $I_{\mathrm{i}}$ may be caused by the reduction in $\mathrm{Na}$ rather than a general depressing effect of depolarization due to increased $\mathrm{K}$, since $I_{\mathrm{i}}$ is retained in the fibers depolarized in 
solutions only deficient in $\mathrm{Cl}$. Therefore it is probable that $\mathrm{Na}$ is mainly responsible for $I_{\mathrm{i}}$.

As mentioned in the Introduction, recent works have suggested the presence in the transverse tubular system of a $\mathrm{Na}$ channel comparable to that of the sarcolemma. If $\mathrm{Na}$ is responsible for $I_{\mathrm{i}}$, the property of this channel is entirely different from that of the sarcolemmal $\mathrm{Na}$ channel as shown by the difference in time course and in sensitivities to tetrodotoxin and picrotoxin. The present results indicate that $I_{\mathrm{i}}$ is insensitive to tetrodotoxin, but is inhibited reversibly with picrotoxin. Picrotoxin also inhibits the hyperpolarization-induced sarcotubular early conductance increase and the moderate depolarization-induced sarcotubular anomalous rectification in normal Ringer solution (TAKEDA, 1975a). These effects of picrotoxin suggest the possibility that the ionic mechanism is identical for these sarcotubular conductance changes and that the moderate depolarizationinduced anomalous rectification represents an increase in sarcotubular conductance when depolarized (TAKEDA, 1975a). If this is the case, the moderate depolarization-induced anomalous rectification may represent a subthreshold sarcotubular response which occurs in normal Ringer solution.

It may be difficult to interpret the potentiation of muscle contraction with picrotoxin (TAKEDA and OOMURA, 1970b, 1971a) without considering the effects of picrotoxin on the sarcotubular conductance changes, although further study is needed to determine the role of these effects in the potentiation.

The failure, so far, to induce the sarcotubular response in normal Ringer solution containing no EDTA or EGTA might indicate that the response is rather non-physiological. However, it is possible that the ionic mechanism of the sarcotubular response works, as mentioned above, as a subthreshold response in normal excitation-contraction coupling, since the sarcotubular response is closely related to the state of $\mathrm{Ca}$ ions as indicated by the augmentation of the response with EDTA or EGTA, and it is established that $\mathrm{Ca}$ ions move within and from the sarcotubular system in excitation-contraction coupling (e.g., SANDOw, 1970).

Finally, the present results suggest that the prolonged depolarizing responses hitherto reported in solutions with Ca-binding anions (FALK and LANDA, 1960; NAKAJIMA et al., 1962; SzAIMI and ToMITA, 1963) involve the sarcotubular response.

The early part of the experiments in this study was done at the Department of Physiology, School of Medicine, Kanazawa University. This study was supported by grant 954186 (General research C) and other grants from the Ministry of Education.

\section{REFERENCES}

Adrian, R. H., Chandler, W. K., and Hodgkin, A. L. (1970) Voltage clamp experiments in striated muscle fibres. J. Physiol., 208: 607-644.

Bastian, J. and NAKAJIMA, S. (1974) Action potential in the transverse tubules and its role in the activation of skeletal muscle. J. Gen. Physiol., 63: 257-278.

Belton, P. and Grundfest, H. (1962) Potassium activation and K spikes in muscle fibers of 
the mealworm larva (Tenebrio molitor). Am. J. Physiol., 203: 588-594.

Bezanilla, F., Caputo, C., González-Serratos, H., and Venosa, R. A. (1972) Sodium dependence of the inward spread of activation in isolated twitch muscle fibres of the frog. J. Physiol., 223: 507-523.

Caputo, C. and DiPolo, R. (1973) Ionic diffusion delays in the transverse tubules of frog twitch muscle fibres. J. Physiol., 229: 547-557.

Costantin, L. L. (1970) The role of sodium current in the radial spread of contraction in frog muscle fibers. J. Gen. Physiol., 55: 703-715.

EisenberG, B. and Eisenberg, R. S. (1968) Selective disruption of the sarcotubular system in frog sartorius muscle. J. Cell Biol., 39: 451-467.

EisenberG, R. S. and Gage, P. W. (1969) Ionic conductance of the surface and transverse tubular membranes of frog sartorius fibers. J. Gen. Physiol., 53: 279-297.

FALK, G. and LANDA, J. F. (1960) Prolonged response of skeletal muscle in the absence of penetrating anions. Am. J. Physiol., 198: 289-299.

GAGE, P. W. and Eisenberg, R. S. (1969) Action potentials, afterpotentials, and excitationcontraction coupling in frog sartorius fibers without transverse tubules. J. Gen. Physiol., 53: $298-310$.

Howell, J. N. (1969) A lesion of the transverse tubules of skeletal muscle. J. Physiol., 201: 515-533.

KaO, C. Y. and Stanfield, P. R. (1968) Actions of some anions on electrical properties and mechanical threshold of frog twitch muscle. J. Physiol., 198: 291-309.

LoRković, H. (1967) The effect of pH on the mechanical activity of the frog toe muscle. $J$. Gen. Physiol., 50: 863-882.

NAKAJIMA, S., IwASAKI, S., and OBATA, K. (1962) Delayed rectification and anomalous rectification in frog's skeletal muscle membrane. J. Gen. Physiol., 46: 97-115.

Sandow, A. (1970) Skeletal muscle. Ann. Rev. Physiol., 32: 87-138.

SzAimi, T. and Tomita, T. (1963) Electrical properties of the frog skeletal muscle membrane in Cl-free sulphate-, ferrocyanide-, and glutamate-Ringer's solutions. Jap. J. Physiol., 13: 641-656.

TAKEDA, K. (1975a) Sarcotubular anomalous rectification of frog sartorius muscle. Jap. J. Physiol., 25: 495-506.

TAKEDA, K. (1975b) Properties of sarcolemmal delayed rectification in glycerol-treated fibers of frog sartorius muscle. Jap. J. Physiol., 25: 507-513.

TAKEDA, K. (1975c) Sarcolemmal slow conductance increase of frog sartorius fibers during hyperpolarization. Jap. J. Physiol., 25: 515-524.

TAKEDA, K. (1975d) Generation of sarcotubular regenerative response in Cl Ringer solution. Zool. Mag., 84: 381 (in Japanese).

TAKEDA, K. (1976) Effects of some ions on sarcotubular regenerative response. J. Physiol. Soc. Japan, 38: 150 (in Japanese).

TAKEDA, K. and OomurA, Y. (1968) Conductance increase causing anomalous rectification in frog muscle in fluoride-rich solution. Proc. Japan Acad., 44: 285-289.

TAKeDA, K. and OomurA, Y. (1970a) Regenerative response in sarcotubular system of frog muscle fibers in F-rich solution. Proc. Japan Acad., 46: 1046-1050.

TAKedA, K. and Oomura, Y. (1970b) Picrotoxin: a potentiator of muscle contraction. Proc. Japan Acad., 46: 1051-1055.

TAKedA, K. and Oomura, Y. (1971a) Potentiation of muscle contraction by high concentration of picrotoxin. J. Physiol. Soc. Japan, 33: 593-594.

TAKEDA, K. and OomurA, Y. (1971b) Enhancement by EDTA of sarcotubular regenerative response produced in F-rich solution. Proc. Japan Acad., 47: 732-735.

TAKedA, K. and Oomura, Y. (1972) Sarcotubular regenerative response induced by EDTA in propionate solution. Proc. Japan Acad., 48: 753-757. 